\title{
Aplicação do Instrumento de Análise Ergonômica - MET na Construção Civil
}

\author{
Laísa Cristina Carvalho \\ Glauco Fabrício Bianchini \\ José Carlos Paliari
}

\section{Introdução}

O setor da construção civil, por sua natureza, requer de seus trabalhadores grande esforço físico para execução da maioria de suas atividades. Além disso, o canteiro de obras pode ser um local inóspito, associado à fadiga física, ao estresse e outros fatores gerados por grande quantidade de trabalhos manuais e pressões por produtividade (SAAD, 2008).

Tais características contribuem para um número significativo de distúrbios musculoesqueléticos relacionados ao trabalho, que poderiam ser evitados com mudanças nos materiais, equipamentos ou organização do trabalho.

A ergonomia aparece, nesse contexto, como alternativa para melhorar as condições de trabalho por meio da adaptação das práticas laborais ao homem. Busca ainda produzir conhecimentos sobre a atividade de trabalho, a fim de alcançar a segurança, a satisfação e o bem-estar dos trabalhadores, propondo o tratamento adequado, evitando prejuízos para empresas e colaboradores, em função de afastamentos, absenteísmos e incapacidades de trabalho (IIDA, 2005). Segundo a Associação Internacional de Ergonomia (IEA, 2000), ergonomia é a disciplina científica pertinente à compreensão das interações entre os seres humanos e os demais 
elementos do sistema, bem como a aplicação de métodos, dados e teorias para aprimorar o bem-estar das pessoas e o desempenho global do sistema.

Nesse processo, a utilização dos instrumentos de análise ergonômica é de suma importância, pois permite a identificação das condições de trabalho que podem levar o trabalhador a sofrer lesões musculoesqueléticas. Por meio desses instrumentos, é possível diagnosticar as situações que mais prejudicam a saúde do operário (SHIDA; BENTO, 2012).

Ressalta-se que questões relacionadas à ergonomia e à segurança do trabalhador não devem ser apenas uma obrigação legal. Cabe ao empregador cumprir a legislação vigente, proporcionando condições adequadas de trabalho, as quais resultarão na satisfação do trabalhador, com reflexos na melhoria do desempenho, redução de absenteísmo e, consequentemente, o aumento da produtividade.

Nesse sentido, este capítulo tem o objetivo de apresentar os procedimentos para aplicar o Instrumento de Análise Ergonômica - MET (Estimativa do Equivalente Metabólico) na Construção Civil, tendo como exemplo o serviço de armação, especificamente no que diz respeito ao recebimento do aço no canteiro de obras.

Inicialmente, é feita uma descrição do conceito de Análise Ergonômica do Trabalho (AET), na qual o instrumento em foco se insere. Em seguida, é feita uma explanação sobre o instrumento de análise ergonômica- MET, no que diz respeito ao conceito, procedimentos para utilização e exemplo de aplicação na construção civil. O presente capítulo se encerra com as considerações finais, nas quais se enfatiza a viabilidade e necessidade de ampliar estudos dessa natureza na construção civil.

\section{AET - Análise Ergonômica do Trabalho}

A Análise Ergonômica do Trabalho (AET) tem como objetivo o conhecimento da situação de trabalho por meio de um processo construtivo e participativo, exigindo conhecimento das tarefas e dificuldades enfrentadas para atingir o desempenho e a produtividade exigida (GUÉRIN et al., 2001).

Daniellou e Béguin (2007) pressupõem que a AET busca os meios de identificar a rede de exigências e constrangimentos na qual se insere a organização e os aspectos que norteiam as decisões sobre o problema a ser tratado no posto de trabalho. $\mathrm{O}$ percurso metodológico é desenvolvido a partir do modelo proposto por Guérin et al. (2001), cuja lógica permite que, conforme as informações e evidências vão se reconstruindo e se edificando, elas sejam aprendidas pelo pesquisador.

A AET é uma intervenção no ambiente de trabalho para o estudo dos problemas causados pela tarefa, decorrentes da atividade humana no meio produtivo, a fim de compreender a situação de trabalho, confrontar aptidões e limitações do trabalhador, diagnosticar as situações críticas e estabelecer sugestões de melhoria ao ambiente de 
trabalho (WISNER, 2003). Segundo Wisner (2003), a AET busca estabelecer e aproximar a compreensão geral de dificuldades relacionadas à organização do trabalho e, como isso, reflete em lesões físicas e transtornos psicofisiológicos.

A AET busca entender a situação geral (demanda) do trabalho prescrito, condições físicas e organizacionais (tarefa) e a forma como o trabalho é realmente executado pelo operador (atividade) (DUL; WEERDMEESTER, 2004). A Figura 1, a seguir, representa as etapas da AET: Situação Geral, Análise da Tarefa, Análise da Atividade e Diagnóstico.

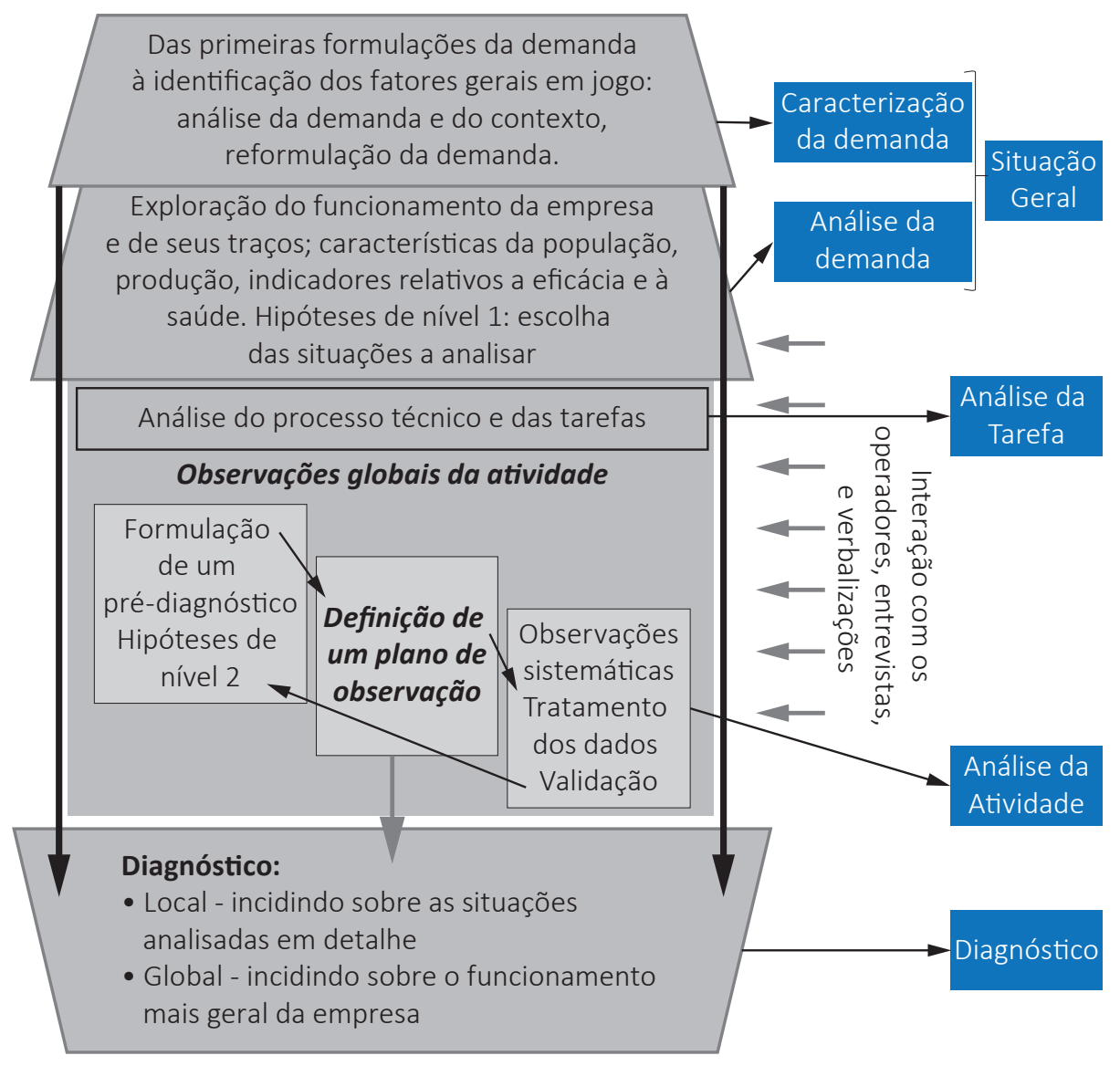

Figura 1 - Etapas da AET. Fonte: Adaptado de Guérin et al., 2001.

A situação geral engloba a caracterização e análise da demanda, em que são levantados dados gerais da empresa e o contexto no qual a empresa se insere. Nessa etapa, também é compreendida a situação do problema proposto pela tarefa 
em análise, levando em consideração o cenário interno e externo da empresa e as condições de trabalho.

A análise da tarefa compreende a assimilação e compreensão de dois aspectos: o trabalho prescrito (a instrução de trabalho) e as condições físicas para execução da tarefa. Portanto, a tarefa corresponde, em primeiro lugar, a um conjunto de objetivos propostos ao trabalhador e a um conjunto de prescrições determinadas para atingir esses objetivos; e, em segundo lugar, a tarefa é tratada como um princípio que impõe uma forma de definir o trabalho em relação ao tempo (GUÉRIN et al., 2001).

A análise da atividade é a etapa na qual se observa o modo operatório do trabalhador, ou seja, a forma como o trabalhador realmente executa o trabalho. Guérin et al. (2001, p.26) define a atividade de trabalho como:

A atividade de trabalho é o elemento central que organiza e estrutura os componentes da situação de trabalho. É uma resposta aos constrangimentos determinados exteriormente ao trabalhador, e ao mesmo tempo é capaz de transformá-los. Estabelece, portanto, pela sua própria realização, uma interdependência e uma interação estreita entre esses componentes.

Portanto, a atividade é definida como aquilo que realmente é executado e a forma como o trabalhador mobiliza e desempenha a tarefa. A atividade é concluída com obtenção do objetivo que foi fixado para ela, a partir do objeto da tarefa.
A atividade não se reduz ao comportamento. comportamento é a parte observável, manifesta, da atividade. A atividade inclui o observável e o inobservável: a atividade intelectual ou mental. A atividade gera o comportamento (FALZON, 2007, p. 9).

Assim a atividade é a base para análise ergonômica do trabalho e é entendida por meio do que o trabalhador faz (ações e decisões tomadas pelo trabalhador para alcançar os objetivos), de que forma o trabalhador faz (o que o trabalhador usa de si para atingir os objetivos) e os modos operatórios (estratégias adotadas pelo trabalhador para alcançar os objetivos) (ABRAHÃO et al., 2009).

Como é observado na Figura 2, a seguir, de um lado, tem-se o trabalhador e suas características (sexo, idade, altura, etc.) e, do outro, a empresa (organização) com suas diretrizes (funcionamento, objetivos, valores, etc.). No núcleo (centro), estão os fatores determinantes para a organização do trabalho (contrato, tarefas prescritas, tarefas reais). Diante das combinações desses fatores, surge a atividade de trabalho executada pelos operadores, a qual resulta em aspectos positivos para empresa 
(produção, qualidade) e aspectos negativos para os trabalhadores (saúde, acidentes, competências).

\section{O operador}

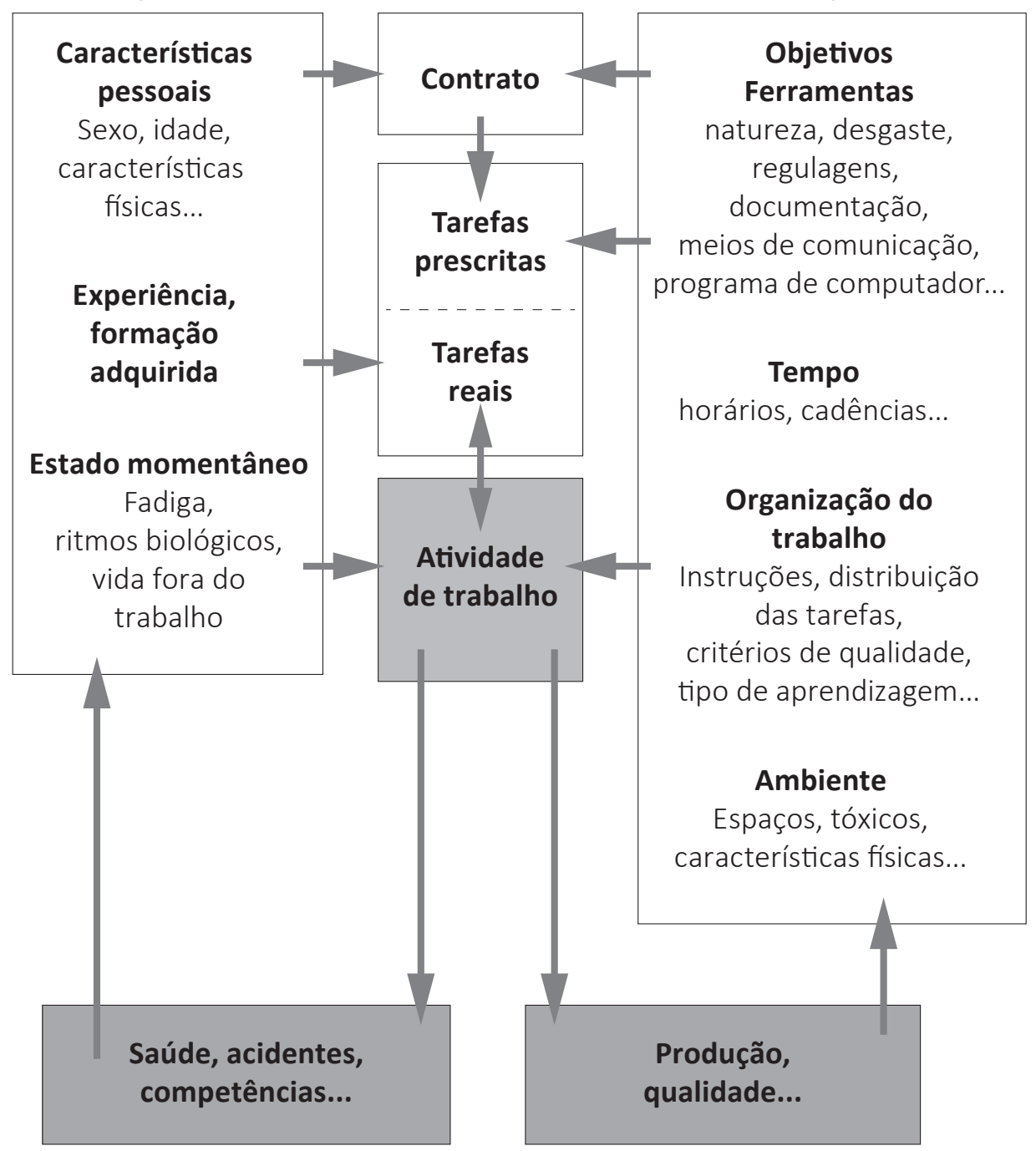

Figura 2 - Função integradora da atividade de trabalho. Fonte: Guérin et al., 2001.

Por fim, a partir da análise da atividade de trabalho, é apresentada a última etapa da AET: o diagnóstico ergonômico, que envolve o levantamento das condições de execução, ambientais e organizacionais do trabalho. 


\section{Instrumento de Análise Ergonômica MET - Equivalente Metabólico}

\subsection{Apresentação}

Segundo Abernethy et al. (1997) e Smith et al. (1997), toda atividade profissional exige um trabalho muscular e um consumo de energia, seja para manter a postura ou para a realização dos movimentos. Isso ocorre a partir da contração das fibras musculares e do gasto energético adicional, em que é superada a taxa de metabolismo de repouso. Para lida (2005), metabolismo de repouso é a quantidade de energia necessária para manter as funções vitais do organismo, sem que haja a realização de qualquer trabalho externo. Esse quantum de energia gasto varia, em adultos, entre $1800 \mathrm{kcal} / \mathrm{dia}$ (homem) e $1600 \mathrm{kcal} / \mathrm{dia}$ (mulher).

Conforme Costa (2013), a determinação exata do gasto calórico para uma pessoa durante a execução do trabalho é obtida por meio de instrumentos conectados ao corpo, com os quais são medidos os batimentos cardíacos, fluxo respiratório, massa corpórea e dados biométricos. A partir desses dados, determina-se o nível de intensidade da atividade física e, consequentemente, o esforço físico envolvido para sua execução.

Ainda segundo a autora, uma amostra da população passa por estudos capazes de quantificar o gasto energético médio despendido em cada atividade, criandose tabelas de referência de taxa metabólica. Assim, é possível aproximar o gasto energético de uma atividade específica ao parâmetro apresentado pela população desejada, podendo-se comparar com outra atividade, ou mesmo outra população.

O equivalente metabólico (MET) é um dos principais instrumentos empregados para descrever as necessidades energéticas requeridas em várias atividades, apresentando seu gasto energético em forma de tabelas (SMITH, 1997). Farinatti (2003) apresenta as análises do MET adaptadas para uma amostra da população brasileira, em forma de tabelas, com 605 atividades cotidianas (lazer, laboral e desportivas) sendo executadas em diferentes intensidades. Estas atividades são apresentadas em tabelas e o cálculo do gasto energético é dado em Kcal $\times \mathrm{Kg}^{-1} \times \mathrm{h}^{-1}$.

Assim, a intensidade física é determinada considerando a relação de Kcal/hora e, a partir desse parâmetro, é possível identificar a atividade como trabalho leve, moderado e pesado, de acordo com o Quadro 1 descrito na "NR 15 - Atividades e operações insalubres".

O MET é utilizado após a abordagem da AET, nas etapas de análise da atividade e diagnóstico, uma vez que apresenta, em números, o gasto energético do trabalhador em cada atividade da tarefa. 
Quadro 1 - Tipos de Atividade.

\begin{tabular}{|l|l|}
\hline Tipo de atividade & Kcal \\
\hline Trabalho leve & 125,00 \\
\hline Sentado, movimentos moderados com braços e troncos (ex: datilografia). & 150,00 \\
\hline Sentado, movimentos moderados com braços e pernas (ex: dirigir). & 150,00 \\
\hline De pé, trabalho leve, em máquina ou bancada, principalmente com os braços. & 180,00 \\
\hline Trabalho moderado & 175,00 \\
\hline Sentado, movimentos vigorosos com braços e pernas. & 220,00 \\
\hline De pé, trabalho leve em máquina ou bancada, com alguma movimentação. & 300,00 \\
\hline De pé, trabalho moderado em máquina ou bancada, com alguma movimentação. & \\
\hline Em movimento, trabalho moderado de levantar ou empurrar. & 440,00 \\
\hline Trabalho pesado & 550,00 \\
\hline Trabalho intermitente de levantar, empurrar ou arrastar pesos (ex.: remoção com pá). & \\
\hline Trabalho fatigante. & \\
\hline
\end{tabular}

Fonte: Brasil, 2014.

\subsection{Processo de Coleta, Processamento de Dados para Utilização do MET e Análise dos Resultados}

\subsubsection{Dados de Entrada}

O procedimento de coleta compreende inicialmente a situação geral, na qual é conhecida a empresa e suas demandas. Em seguida, dá-se a análise da tarefa e atividade do serviço a ser analisado, sob o ponto de vista da empresa e do trabalhador. Assim, no contexto da empresa, é necessário compreender o processo de como essa tarefa é transmitida ao trabalhador, ou seja, se há um procedimento de execução de serviço, treinamento antes do início da atividade ou se a tarefa é repassada ao trabalhador apenas de forma verbal pelo seu supervisor imediato. Com relação à atividade realizada pelo trabalhador, é importante entender como ele a executa, ou seja, se é de acordo com o procedimento da empresa (caso possua) ou conforme seu tempo de serviço e experiência. Além disso, é preciso verificar se as ferramentas estão adequadas e se o espaço do posto de trabalho é suficiente. Em outras palavras, é importante compreender como o trabalhador enxerga a atividade e sua execução.

Assim, com as informações obtidas sobre a tarefa, é possível analisar a atividade, compreendendo e identificando as variabilidades do posto de trabalho e do trabalhador, no intuito de entender o modo operatório- termo próprio da ergonomia, que caracteriza as diferentes maneiras de se executar uma mesma tarefa - desse agente da construção civil. Essa identificação leva à localização de competências não 
reconhecidas pela empresa, capazes de contribuir para evolução profissional ou para investimentos técnicos.

As informações obtidas mediante contato pessoal com a empresa e seus trabalhadores e filmagens, geram os seguintes dados de entrada para o instrumento de análise ergonomica MET:

- Os códigos da atividade (MET) são obtidos no Compêndio de Atividades Físicas: códigos, atividades e intensidade em MET's, apresentados por Farinatti (2003) e exemplificados no item 4.3. Informa como a tarefa é codificada em termos de função realizada, tipo específico e intensidade. 0 Compêndio pode ser usado para estudos com diferentes objetivos;

- Tempo das atividades na tarefa (etapas do serviço, em segundos): tempo em que se mede a quantidade de vezes que uma ação aparece ao longo da tarefa, quantas vezes se repete a ação (ciclo);

- Duração da tarefa e do ciclo do trabalho (em segundos): o tempo total gasto para cumprir a tarefa, a tarefa representa o ciclo de trabalho;

- Peso de um homem adulto médio (70 kg): indivíduo de referência estipulado para uso no MET.

Define-se o tempo de realização da tarefa como sendo uma hora, de tal forma que os valores resultantes sejam obtidos em Kcal/hora.

Procedimento de cálculo utilizado:

- Quantidade de ciclos = Tempo de realização da tarefa $\times 3.600$ / Duração do ciclo;

- Tempo da etapa $(h)=$ Duração da etapa $\times$ Quantidade de ciclos / 3.600;

- $\mathrm{Kcal} / \mathrm{hora}=\Sigma$ (Tempo da etapa (h) $\times$ MET $\times$ Peso adulto médio) .

O cálculo do dispêndio de energia na execução da tarefa foi dado pelo somatório dos dispêndios de energias em cada Atividade (etapa) que compõe a tarefa.

\subsubsection{Coleta de Dados}

Todos os dados são obtidos por meio de entrevistas informais e questionários semiestruturados com funcionários da obra, no intuito de compreender as situações de trabalho, tanto de ordem ambiental como técnica e organizacional, e de caracterizar o trabalhador, de modo a obter informações, tais como: peso, altura, tempo de serviço, nível de escolaridade, etc.

É realizada uma observação simples e direta dos trabalhadores, na qual o pesquisador permanece alheio às atividades do grupo observado e não interfere nas situações de trabalho. Essa observação está associada a registros fotográficos 
e filmagens com tempo variável conforme a complexidade da atividade, a fim de caracterizar a atividade desenvolvida e auxiliar na análise dos movimentos e posturas de cada trabalhador.

Para melhor compreenssão das etapas da coleta de dados, é apresentada, a seguir, a Figura 3, em que é especificado o passo a passo desse processamento.

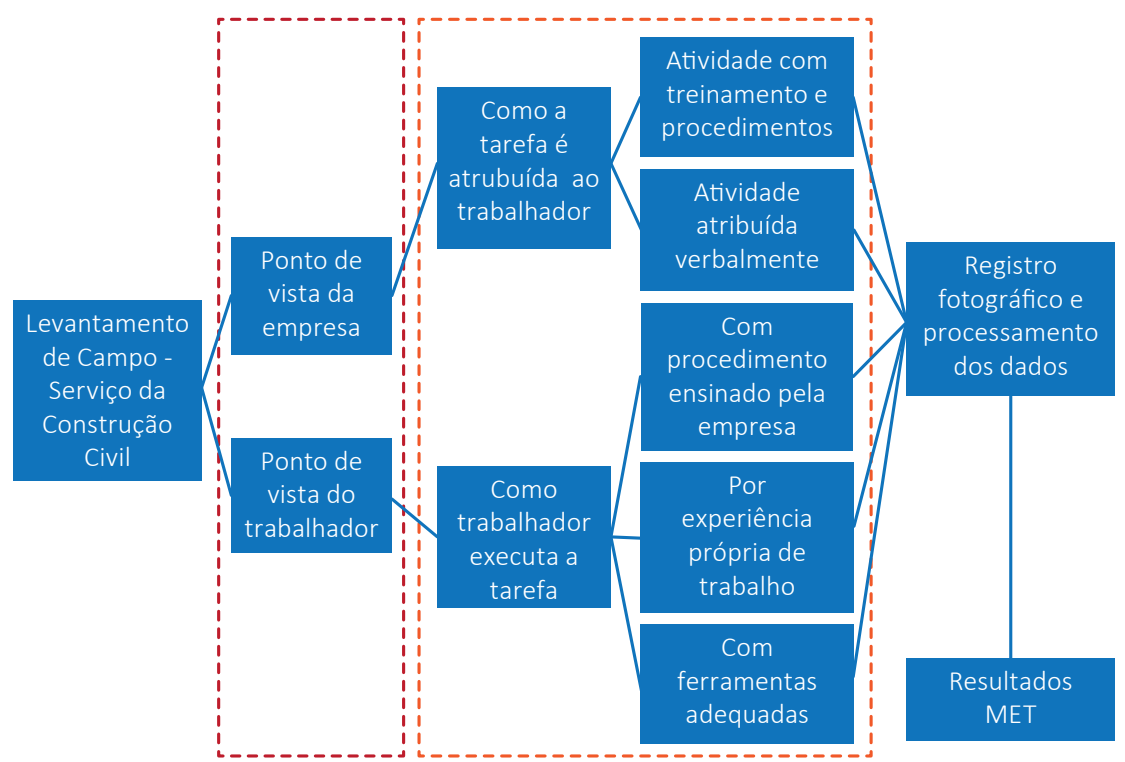

Figura 3 - Etapas da coleta de dados. Fonte: Autores.

O registro da tarefa ocorre em períodos distintos durante a jornada de trabalho, com o propósito de representar de modo fiel e real o cenário cotidiano da tarefa no canteiro de obras. Esse registro fotográfico e de filmagens ajuda o pesquisador nas análises de laboratório e facilita a obtenção dos tempos de ciclo (tempos para realizar cada atividade da tarefa). A partir desses dados, faz-se o uso do instrumento de análise ergonômica MET, que processa essas informações de forma qualitativa e quantititava de maneira a facilitar a sua compreensão, explicação e utilização.

\subsubsection{Processamento de Dados}

Partindo do princípio que as filmagens fornecem a possibilidade de obtenção de dados e possibilitam uma nova observação sem que se precise retornar ao local de trabalho, obtem-se os principais dados utilizados nas avaliações e no instrumento de análise ergonômica. Esses dados são identificados ao se assistir cada vídeo relacionado à tarefa, em que é possível determinar o tempo gasto em cada atividade da tarefa e quantas vezes essa atividade aconteceu para se cumprir o objetivo da tarefa. 


\subsubsection{Análise dos Resultados}

A análise dos resultados leva ao diagnóstico das situações de trabalho a que estão sujeitos os operários da construção civil. O diagnóstico se dá de modo global (ambiente de trabalho) e local (situação de trabalho). Tal etapa abrange as condições técnicas para a execução do trabalho, as condições ambientais em que a atividade ocorre, além das condições organizacionais do trabalho.

Assim, o diagnótico também busca propor melhorias com base na ergonomia de correção e concepção, a fim de motivar participação conjunta dos setores da empresa, com intuito de discutir a organização do trabalho, utilizar estratégias para melhorar a comunicação e o relacionamento da equipe, oferecer treinamentos e orientar os trabalhadores sobre os riscos a que estão expostos no canteiro de obras.

\section{Exemplo de Aplicação do Instrumento de Análise Ergonômica - MET}

Exemplifica-se a aplicação do instrumento de análise ergonômica - MET, focando a execução do serviço de armação, cujo resultado é oriundo de um estudo de caso realizado em um canteiro de obras localizado no município de São Carlos-SP, especificamente no que diz respeito ao recebimento do aço nos canteiros de obras.

\subsection{AET}

Para a AET, é necessária a compreensão do fluxograma de processos da tarefa e como essa tarefa é executada (conjunto de atividades). Na Figura 4, apresenta-se o fluxograma dos processos, tendo-se como tarefas o recebimento do aço no canteiro de obras, sua estocagem, processamento e aplicação final.

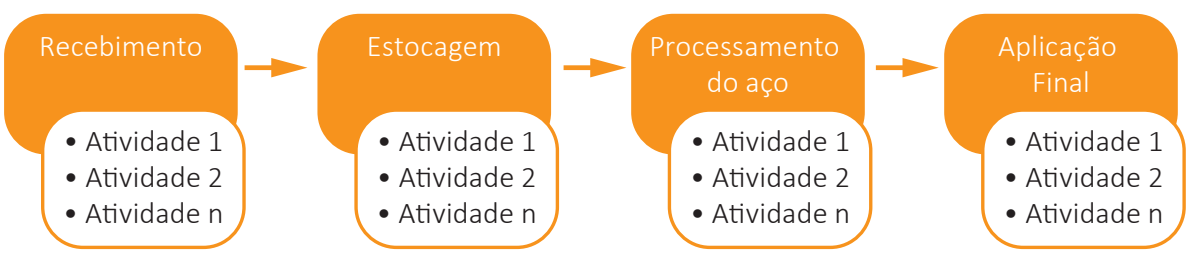

Figura 4 - Fluxograma de Processos (Exemplo: Serviço de Armação). Fonte: Autores.

Após entendimento do fluxograma de processos contendo as tarefas e suas respectivas atividades e de posse das filmagens das ações, é possível determinar quais são executadas para atingir o objetivo da tarefa e o respectivo modo operatório dos trabalhadores (o porquê se fazer daquele determinado modo). Com o detalhamento das atividades, é possível determinar o tempo de ciclo de cada uma e quantas vezes se repetem ao longo da tarefa. No Quadro 2, é apresentada a tarefa de recebimento do aço e suas respectivas atividades, para as quais se apresentam outras informações sobre o modo operatório, obtidas por meio da filmagem, conforme prescreve a AET. 


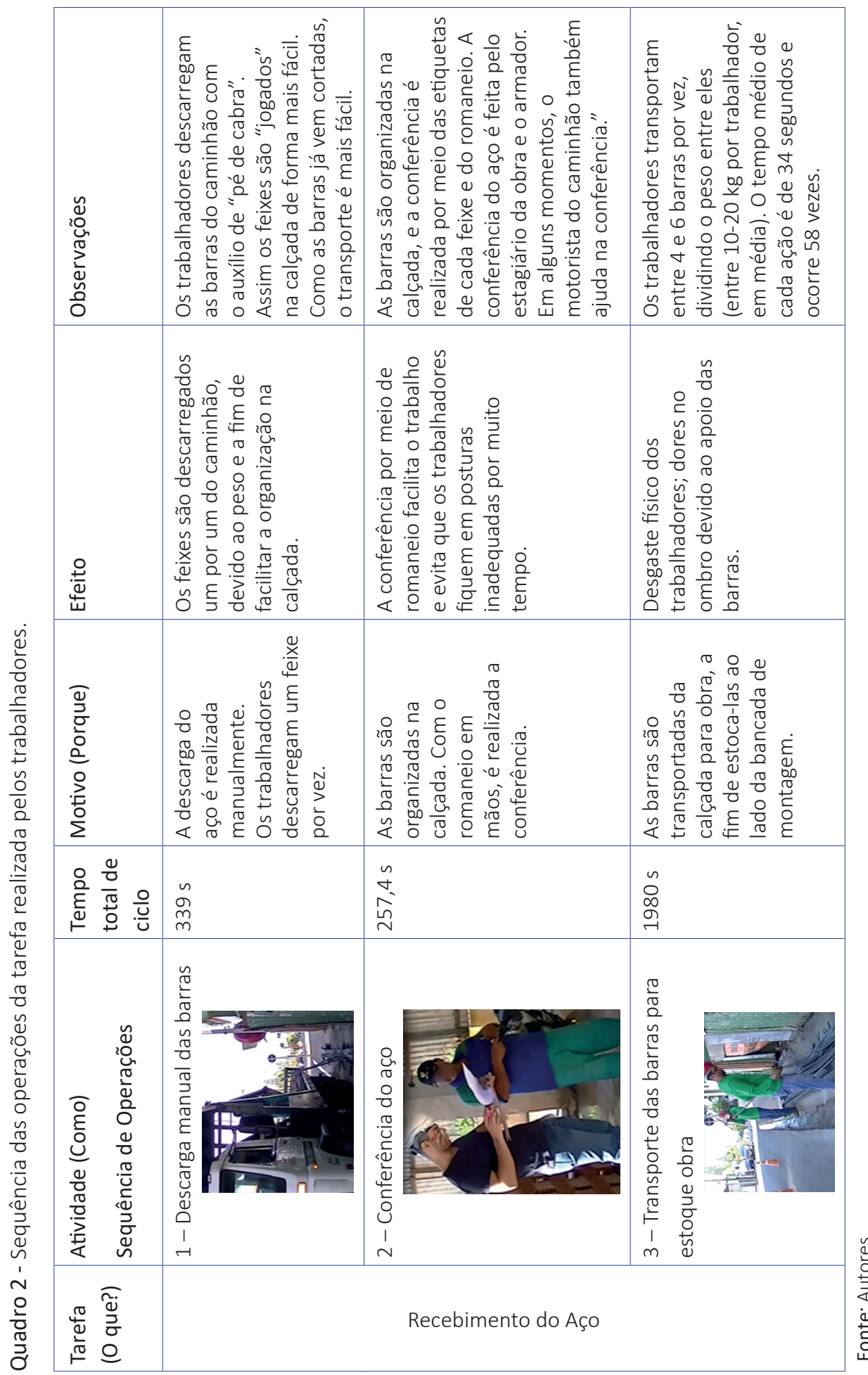




\subsection{Dados de Entrada}

Os dados determinantes de entrada para o cálculo do dispêndio de energia são:

- Código das atividades do serviço de armação;

- Tempo das atividades do serviço de armação (em segundos);

- Duração da tarefa e do ciclo do trabalho (em segundos);

- Peso de um homem adulto médio.

Procedimento de cálculo utilizado:

- Quantidade de ciclos = Tempo de realização da tarefa $\times$ 3.600/Duração do ciclo;

- Tempo da etapa $(h)=$ Duração da etapa $\times$ Quantidade de ciclos/3.600;

- $\mathrm{Kcal} /$ hora $=\Sigma($ Tempo da etapa $(\mathrm{h}) \times \mathrm{MET} \times$ Peso adulto médio $)$.

\subsection{Exemplo de Cálculo}

Para exemplificar a aplicação e cálculo do gasto energético (Kcal/hora) conforme demonstra o MET, foi analisado o serviço de recebimento do aço. A visita no canteiro de obras resultou na sequência de atividades da tarefa de recebimento do aço no canteiro de obras, conforme apresentado no Quadro 2. Para os cálculos do gasto energético nessa tarefa, foram consideradas as seguintes condições:

- Peso médio dos trabalhadores envolvidos na tarefa: 70,0kg;

- Determinação da duração dos ciclos: o ciclo é determinado por meio do tempo exigido para se executar a atividade (coluna 3 do Quadro 2). Os tempos médios foram determinados a partir do cálculo da média dos tempos para cada atividade obtidos nas filmagens;

- O ciclo da tarefa (tempo total de todas as atividades para se concluir o objetivo da tarefa) possui duração média de 2576,4 segundos, que equivale a 42,94 minutos ou 0,72 horas;

- Durações médias de cada atividade durante o recebimento do aço:

- Descarga manual das barras na calçada =339s;

- Conferência do aço com romaneio = 257,4s;

- Transporte das barras para estoque no interior da obra $=34 \mathrm{~s}$.

- Tempo gasto diariamente em cada operação da tarefa:

- Descarga manual das barras na calçada =339s; 
- Conferência do aço com romaneio = 257,4s;

- Transporte das barras para estoque no interior da obra $=1980 \mathrm{~s}$.

Código MET de cada atividade (Quadro 3, extraído de FARINATTI, 2003): O valor do MET é determinado pela atividade específica. Quando não há diretamente a atividade específica da construção civil, é realizada a correlação. Por exemplo, o código 11050 representa a atividade de transporte de cargas pesadas, o que caracteriza o transporte manual das barras:

Quadro 3-MET.

\begin{tabular}{|l|l|l|l|}
\hline Código & MET & Contexto Principal & Atividade específica (exemplos) \\
\hline 11050 & 8,0 & Atividades Ocupacionais & $\begin{array}{l}\text { Transporte de cargas pesadas } \\
\text { (por exemplo - tijolos) }\end{array}$ \\
\hline 11610 & 3,0 & Atividades Ocupacionais & $\begin{array}{l}\text { Em pé, leve/moderado (trabalhos } \\
\text { manuais pesados, etc.) }\end{array}$ \\
\hline
\end{tabular}

Fonte: Adaptado de Farinatti (2003).

- Descarga manual das barras na calçada = Código 11050- MET = 8,0;

- Conferência do aço com romaneio = Código 11610- MET = 3,0;

- Transporte das barras para estoque no interior da obra = Código 11050$\mathrm{MET}=8,0$.

- Cálculo da kcal gasta na atividade ao longo do dia em horas:

- Descarga manual das barras na calçada $=8,0 \times 70,0 \times 0,09=50,4 \mathrm{kcal}$;

- Conferência do aço com romaneio = 3,0 × 70,0 ×0,07 = 14,7 kcal;

- Transporte das barras para estoque no interior da obra $=8,0 \times 70,0 \times$ $0,55=308 \mathrm{kcal}$.

- Determinação da relação Kcal/ hora: 371,1/0,72 = 515,42.

De acordo com o resultado apresentado no Quadro 4, a operação que demandou maior esforço físico durante a jornada de trabalho foi a de número 3 (consumo 308 kcal), taxa justificada pelo número de vezes (58) em que as barras são transportadas. Comparando os resultados com os prescritos na "NR-15 - Atividades e Operações Insalubres" (Quadro 2 deste capítulo), conclui-se que, para um trabalhador de porte médio, a atividade de recebimento do aço pode ser considerada um trabalho pesado (fatigante) do ponto de vista da taxa de metabolismo.

Diante desse resultado, os gestores do serviço poderiam propor que tal transporte seja realizado por carrinho específico, grua ou que o aço seja descarregado diretamente no local de estocagem, evitando esse tipo de transporte. 
Quadro 4 - Resultados obtidos no MET.

\begin{tabular}{|l|l|l|l|}
\hline Sequência das etapas & 1 & 2 & 3 \\
\hline Tempo diário no ciclo $(\mathrm{h})$ & 0,09 & 0,07 & 0,55 \\
\hline Código & 11050 & 11610 & 11050 \\
\hline MET & 8,0 & 3,0 & 8,0 \\
\hline Kcal & 50,4 & 14,7 & 308 \\
\hline \multicolumn{2}{r|}{ Trabalho Pesado = MET > 440 (NR-15 - Atividades e Operações Insalubres) } \\
\hline
\end{tabular}

Fonte: Autores.

\section{Conclusões}

A ergonomia ainda é pouco aplicada na construção civil e, especialmente, no subsetor de edificações, no qual os trabalhadores ainda utilizam ferramentas e equipamentos manuais, muitas vezes danificados e inadequados para realização de suas atividades de trabalho.

Por meio da AET, é possível caracterizar de que forma o trabalho está sendo executado e quais as suas consequências para empregadores e trabalhadores. As melhorias nas condições de trabalho só podem ser executadas se houver uma perfeita compreensão da diferença entre a tarefa prescrita e a atividade realizada. Nesse sentido, os instrumentos de análise ergonômica auxiliam no processo de identificação das situações críticas de trabalho, quantificando e comparando os valores obtidos em campo com os valores determinados pela literatura.

Este capítulo apresentou o instrumento de análise ergonômica MET, detalhando seus procedimentos de aplicação e formas de obtenção de dados. A atividade selecionada para análise foi caracterizada como trabalho pesado, podendo ser fatigante para os trabalhadores em questão.

\section{Referências}

ABRAHÃO, J.I.; SZNELWAR, L.; SILVINO, A.; SARMET, M.; PINHO, D. Introdução à ergonomia: da prática à teoria. São Paulo: Editora Blucher, 2009.

ABERNETHY, B.; KIPPERS, V.; MACKINNON, L.T.; NEAL, R.J.; HANRAHAN, S. The Biophysical Foundations of Human Movement. Human Kinects Publishers, Australia. 425p. 1997. 
BRASIL. Ministério do Trabalho e Emprego. Norma Regulamentadora 15 (NR-15): Atividades e Operações Insalubres. 2014. Disponível em: <http://portal.mte.gov.br/data/ files/8A7C816A47594D040147D14EAE840951/NR-15\%20(atualizada\%202014).pdf>. Acesso em: nov. 2014.

COSTA, S.E.A. Análise Ergonômica do Trabalho de colheita de citros: comparativo dos métodos de colheita manual e semimecanizada. 2013. 152f. Dissertação (Mestrado) Universidade Federal de São Carlos, São Carlos, 2013.

DANIELLOU, F.; BÉGUIN, P. Metodologia da ação ergonômica: abordagens do trabalho real. In: FALZON, P. (Ed.). Ergonomia. São Paulo: Edgard Blucher, 2007.

DUL, J.; WEERDMEESTER, B. Ergonomia prática. São Paulo: Edgard Blucher, 2004.

FALZON, P. Natureza, objetivos e conhecimentos da ergonomia: elementos de uma análise cognitiva da prática. In: FALZON, P. (Ed.). Ergonomia. São Paulo: Edgard Blucher, 2007. p. 3-19.

FARINATTI, P.T.V. Apresentação de uma versão em português do compêndio de atividades físicas: uma contribuição aos pesquisadores e profissionais em fisiologia do exercício. Rev. Bras. Fisiol. Exerc. 2003; v. 2, p. 177-208.

GUÉRIN, F. et al. Compreender o trabalho para transformá-lo: a prática da ergonomia. São Paulo: Edgard Blucher, 2001.

IEA. Definição Internacional de ergonomia. Aprovação na Reunião do Conselho Científico da International Ergonomics Association. San Diego- USA. 2000.

IIDA, I. Ergonomia, projeto e produção. São Paulo: Edgard Blucher, 2005.

SAAD, V.L. Análise Ergonômica do Trabalho do Pedreiro: o assentamento de tijolos. 2008. 124f. Dissertação (Mestrado em Engenharia de Produção) - Campus Ponta Grossa, Universidade Tecnológica Federal do Paraná, Ponta Grossa, 2008.

SHIDA, G.J.; BENTO, P.E.G. Método e Ferramentas Ergonômicas que Auxiliam na Análise de Situação de Trabalho. In: CONGRESSO NACIONAL DE EXCELÊNCIA EM GESTÃO, n. 8, 2012, Rio de Janeiro, Niterói. Anais eletrônicos... Disponível em: <http://www.excelenciaemgestao. org/Portals/2/documents/cneg8/anais/T12_0496_3097.pdf>. Acesso em: ago. 2014.

SMITH. L.K. Cinesiologia Clínica de Brunnstrom. Editora manole. Ed 5. São Paulo. 1997.

WISNER, A. A inteligência no trabalho: textos selecionados de ergonomia. Roberto Leal Ferreira (Trad.). São Paulo: FUNDACENTRO, 2003. 190p. 


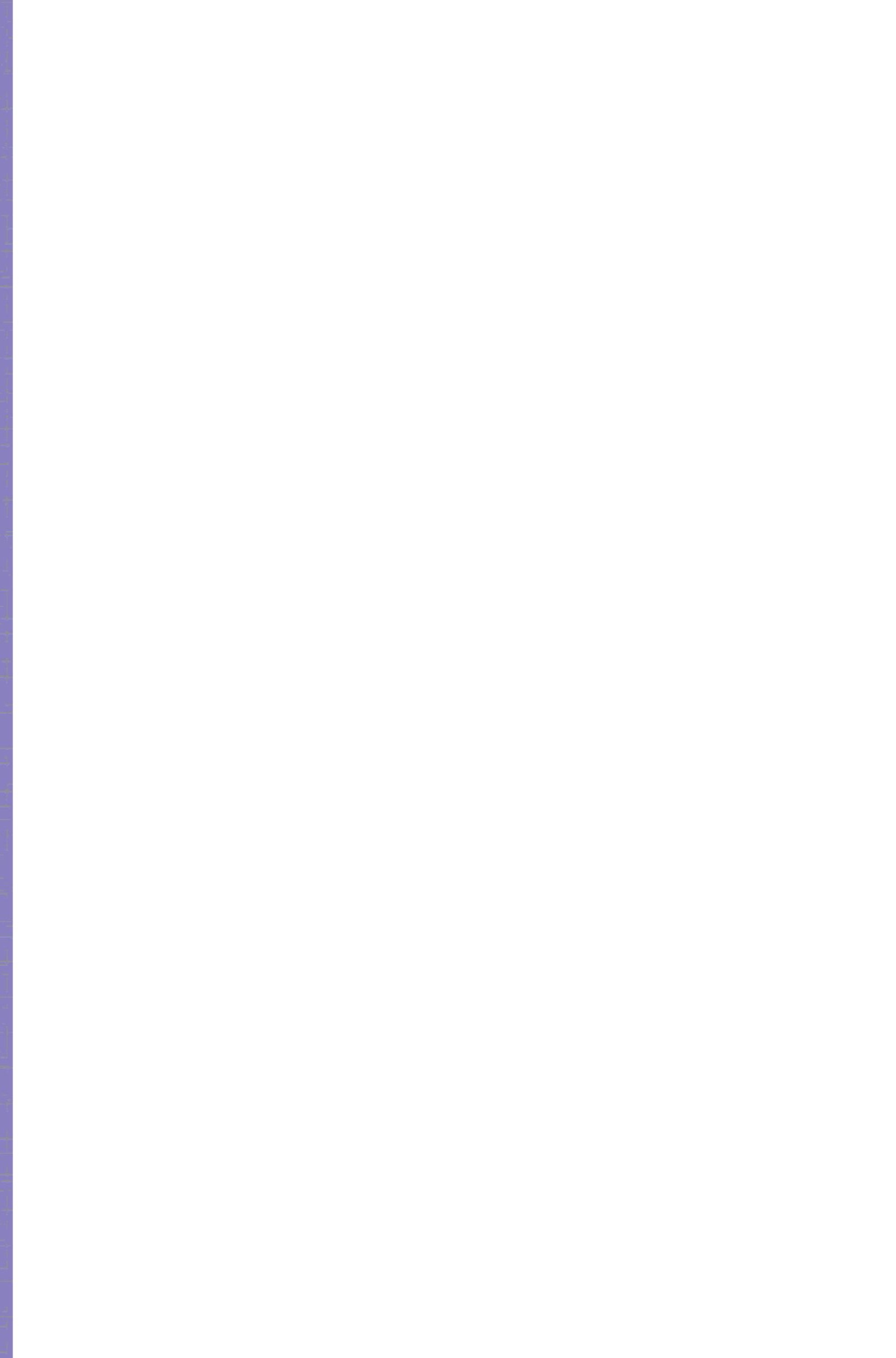

